\title{
Oxidation of olefins catalyzed by new binaphthyl-ruthenium(III) complexes
}

\author{
Laurent Provins $^{* 1, \dagger}$ and Shun-Ichi Murahashi ${ }^{1,2}$ \\ ${ }^{1}$ Department of Chemistry, Graduate School of Engineering Science, Osaka University, 1-3 \\ Machikaneyama, Toyonaka, Osaka 560-8531, Japan \\ ${ }^{2}$ Department of Applied Chemistry, Okayama University of Science, Ridaicho 1-1, Okayama \\ 700-0005, Japan \\ E-mail: Laurent.Provins@UCB-Group.com
}

\section{Dedicated with deep respect to Professor Alain Krief on the occasion of his $65^{\text {th }}$ birthday}

\begin{abstract}
The synthesis of new binaphthyl ruthenium(III) catalysts is described. The oxidation of olefins using these catalysts and iodobenzene diacetate has been studied. We have surprisingly found that $\alpha$-ketoacetates are formed together with the corresponding epoxides, the selectivity of the reaction depending upon the olefin substitution and the catalyst used. A mechanistic rationalization of the results is described.
\end{abstract}

Keywords: Ruthenium catalyst, oxidation, olefin, ketoacetate, epoxide

\section{Introduction}

Oxidative transformation of organic substrates is fundamental for organic synthesis. We have been working on the ruthenium catalyzed oxidation reaction of various substrates, ${ }^{1-2}$ such as amines, ${ }^{3-4} \beta$-lactams, ${ }^{5}$ alkenes $^{6}$ and non-activated hydrocarbons ${ }^{7}$ under mild conditions highly efficiently. Transition metal-catalyzed asymmetric reactions now constitute one of the most widely used methods to have an easy access to key scaffolds. ${ }^{8}$ Several class of ligands such as salens, cinchona alkaloids, bisoxazolines have emerged over the last ten years, but it appears that there is still an unmet need for a new class of ligand.

We report herein synthesis of a new class of binaphthyl-derived ligands and their ruthenium(III) complexes, and use for oxidation of alkenes.

\footnotetext{
† Present address: UCB, Global Chemistry, R\&D, Chemin du Foriest R4, B-1420 Braine-L’Alleud, Belgium. Fax: +32-2-3863669
} 


\section{Results and Discussion}

Manganese complexes proved to be very interesting catalysts for the epoxidation of unactivated olefins, ${ }^{9-11}$ oxidations of silylethers ${ }^{12}$ and non-activated hydrocarbons; ${ }^{13-14}$ however, the ruthenium complexes remained poorly studied. We have therefore decided to prepare a series of ligands derived from various acetoacetates and cyclic or acyclic diketones.

In order to enlarge the variety of ligands and complexes, we have chosen binaphthyldiamine 2 as chiral diamine. It should be noticed that the use of binaphthyldiamine for such purposes is not well documented. Only a few papers deal with the formation of binaphthyl-salen ligands and manganese complexes and their use for asymmetric epoxidation of olefins. ${ }^{15}$

Therefore, it seemed very interesting to study i) the synthesis of new binaphthyl-modified ketoester or diketone ligands, ii) the formation of new ruthenium(III) complexes, and iii) the catalytic activity for epoxidation of olefins.

The binaphthyl-modified ligands $\mathbf{3}$ were efficiently synthesized in two steps starting from readily available acetoacetates or 1,3-diketones which are first formylated then condensed with binaphthyldiamine $2 .{ }^{11}$ The sterochemistry of ligands $\mathbf{3}$ has not been unambiguously proved.

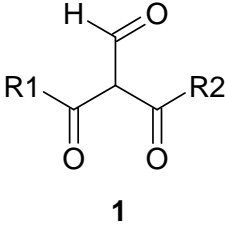

1

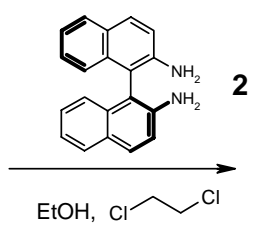

$70^{\circ} \mathrm{C}$

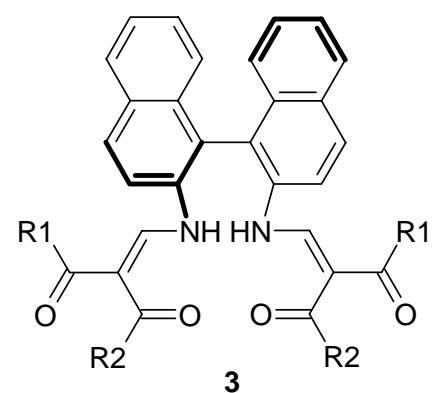

\section{Scheme 1}

Table 1. Binaphthyl-modified ligands

\begin{tabular}{ccccc}
\hline Entry & $\mathrm{R} 1$ & $\mathrm{R} 2$ & Ligand & Yield \\
\hline 1 & & $\mathrm{Me}$ & 3a & $59 \%$ \\
2 & $\mathrm{MeO}$ & $\mathrm{Me}$ & $3 \mathbf{b}$ & $69 \%$ \\
3 & $\mathrm{Ph}$ & $\mathrm{Me}$ & $3 \mathbf{3}$ & $59 \%$ \\
4 & $-\mathrm{CH}_{2} \mathrm{CMe}_{2} \mathrm{CH}_{2-}$ & 3d & $88 \%$ \\
\hline
\end{tabular}

Formylated acetoacetate 1a derived from 2-adamantanol was synthesized as previously reported. ${ }^{11,16,17}$ The formylation reactions of commercially available benzoylacetone ${ }^{11}$ (entry 3) and dimedone ${ }^{18}$ (entry 4 ) were performed very efficiently as shown on Scheme 2. 

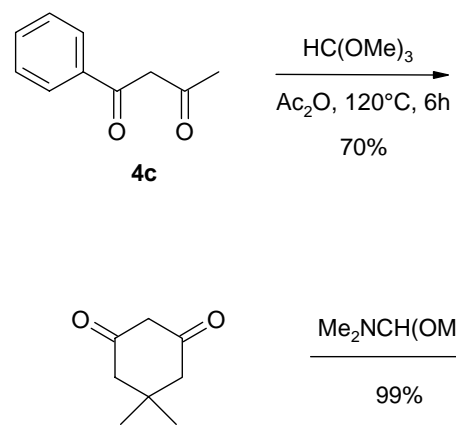

4d<smiles>CO/C=C(\C(C)=O)C(=O)c1ccccc1</smiles>

$\underset{\text { THF- }{ }_{2} \mathrm{O}, \mathrm{rt}, 2 \mathrm{~h}}{\mathrm{HCl} 5 \%}$
$80 \%$

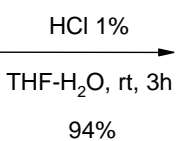

$5 d$<smiles>CC(=O)C(C=O)C(=O)c1ccccc1</smiles><smiles>CC1(C)CC(=O)C(C=O)=C(O)C1</smiles>

$1 d$

\section{Scheme 2}

Ruthenium salen-type complexes have been prepared using $\mathrm{K}_{2}\left[\mathrm{RuCl}_{5}\left(\mathrm{H}_{2} \mathrm{O}\right)\right]$, ${ }^{19}$ and we examined the formation of the complexes derived from our ligands. The conditions previously reported for the complexation $(\mathrm{EtOH} \text {, reflux })^{19}$ proved however to be unsuccessful in this case. A careful study of several reactions conditions (see table) performed on a model ligand $\mathbf{3 b}$ showed that the use of a particular base, DBU, in DMF, is required to obtain reasonable and reproducible yields of the corresponding complex (Table 2). Other bases such as sodium hydride, DBN, cesium carbonate, sodium methoxide led to complete recovery of the starting ligand.

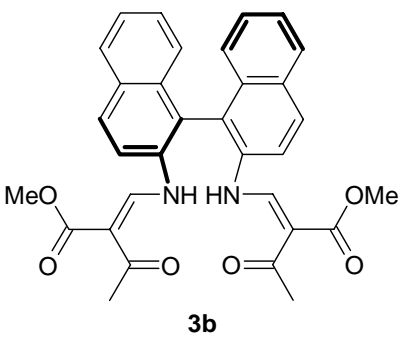

$3 b$

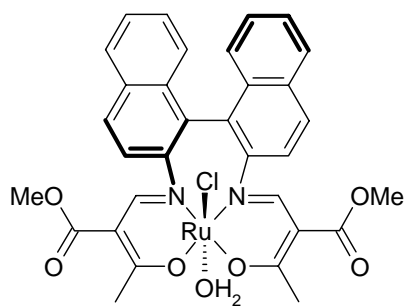

$6 b$

\section{Scheme 3}

Table 2. Binaphthyl-ruthenium(III) complexes

\begin{tabular}{ccccccc}
\hline Entry & Ligand & $\mathrm{Ru}(\mathrm{III})$ salt & Base & Solvent & $\begin{array}{c}\text { Temperature } \\
\left({ }^{\circ} \mathrm{C}\right)\end{array}$ & Yield \\
\hline 1 & $\mathbf{3}_{\mathbf{b}}$ & $\mathrm{K}_{2}\left[\mathrm{RuCl}_{5}\left(\mathrm{H}_{2} \mathrm{O}\right)\right]$ & - & $\mathrm{EtOH}$ & 80 & no reaction \\
2 & $\mathbf{3}_{\mathbf{b}}$ & $\mathrm{K}_{2}\left[\mathrm{RuCl}_{5}\left(\mathrm{H}_{2} \mathrm{O}\right)\right]$ & $\mathrm{MeONa}$ & $\mathrm{EtOH}$ & 80 & $£$ \\
3 & $\mathbf{3}_{\mathbf{b}}$ & $\mathrm{K}_{2}\left[\mathrm{RuCl}_{5}\left(\mathrm{H}_{2} \mathrm{O}\right)\right]$ & $\mathrm{NaH}$ & $\mathrm{DMF}$ & 120 & no reaction \\
4 & $\mathbf{3}_{\mathbf{b}}$ & $\mathrm{K}_{2}\left[\mathrm{RuCl}_{5}\left(\mathrm{H}_{2} \mathrm{O}\right)\right]$ & $\mathrm{DBU}$ & $\mathrm{DMF}$ & 120 & $30 \%$ \\
5 & $\mathbf{3}_{\mathbf{b}}$ & $\mathrm{K}_{2}\left[\mathrm{RuCl}_{5}\left(\mathrm{H}_{2} \mathrm{O}\right)\right]$ & $\mathrm{DBN}$ & $\mathrm{DMF}$ & 120 & traces \\
6 & $\mathbf{3}_{\mathbf{b}}$ & $\mathrm{K}_{2}\left[\mathrm{RuCl}_{5}\left(\mathrm{H}_{2} \mathrm{O}\right)\right]$ & $\mathrm{Cs}_{2} \mathrm{CO}_{3}$ & $\mathrm{DMF}$ & 120 & no reaction \\
8 & $\mathbf{3}_{\mathbf{c}}$ & $\mathrm{K}_{2}\left[\mathrm{RuCl}_{5}\left(\mathrm{H}_{2} \mathrm{O}\right)\right]$ & $\mathrm{DBU}$ & $\mathrm{DMF}$ & 120 & $33 \%$ \\
9 & $\mathbf{3}_{\mathbf{d}}$ & $\mathrm{K}_{2}\left[\mathrm{RuCl}_{5}\left(\mathrm{H}_{2} \mathrm{O}\right)\right]$ & $\mathrm{DBU}$ & $\mathrm{DMF}$ & 120 & $15 \%$ \\
\hline
\end{tabular}

$£:$ irreproducible yields 
Application of these conditions to the other ligands $\mathbf{3 c}$ and $\mathbf{3 d}$ has been performed, and a series of ruthenium(III) complexes has been obtained in moderate but reproducible yields. All of them have been characterized by IR and FAB-mass spectrometry that confirms the presence of both chlorine and water ligands on ruthenium.

Several papers dealing with asymmetric epoxidations of unactivated olefins by ruthenium complexes have been published in the last few years ${ }^{20-22}$ but, compared with Mn-salen typecatalysts, only a few examples of ruthenium catalysts have been studied.

Nishiyama ${ }^{21}$ has shown that, in the case of the ruthenium(pybox) complexes, iodobenzene diacetate was among the best oxidants (and by far superior to iodosobenzene) for olefins oxidation. In order to make some comparisons with that system, we studied the epoxidation of trans-stilbene 7a under the reported conditions ( $\mathrm{PhI}(\mathrm{OAc})_{2}$ (3 eq.), $\left.\mathrm{PhMe}, \mathrm{rt}, 96 \mathrm{~h}\right)$ using our binaphthyl-substituted ruthenium(III) catalyst $\mathbf{6 c}$.

We have surprisingly found that trans-stilbene oxide 8a is not the only product formed in the reaction. A nearly equimolar amount of acetic acid 2-oxo-1,2-diphenyl-ethyl ester (9a) was isolated and its structure was characterized.
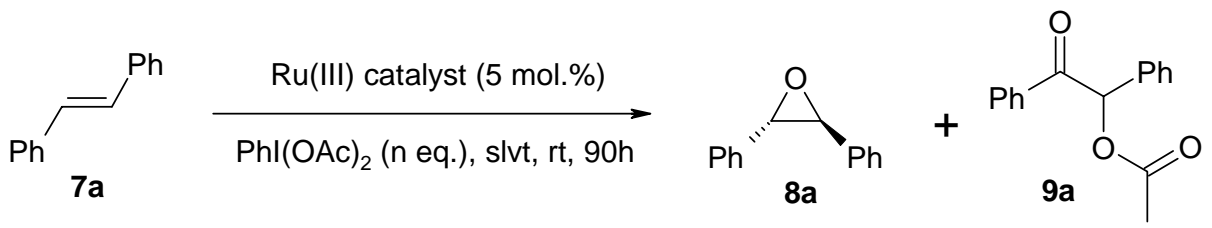

\section{Scheme 4}

Table 3. Oxidation of trans-stilbene

\begin{tabular}{cccccc}
\hline Entry & $\mathrm{n}$ & solvent & additive & Conversion $(\%)$ & $\mathbf{8}_{\mathbf{a}} / \mathbf{9}_{\mathbf{a}}$ \\
\hline 1 & 3 & $\mathrm{PhMe}$ & - & $>95(71)$ & $53 / 47^{\boldsymbol{S}}$ \\
2 & 6 & $\mathrm{PhMe}$ & - & $>95$ & $45 / 55$ \\
3 & 3 & $\mathrm{PhMe}$ & $\mathrm{NaOAc}$ & $\sim 60$ & $85 / 15^{\&}$ \\
4 & 3 & $\mathrm{MeCN}$ & - & $\sim 80$ & $>95 / 5$ \\
\hline
\end{tabular}

( ): isolated yield. ${ }^{\&}$ important amounts of benzaldehyde found, oxidative cleavage favored. ${ }^{\$}$ e.e of the epoxide (4\%) was determined by chiral HPLC (chiralcel OD-H, hexane-isopropanol: $90 / 10,0.5 \mathrm{ml} / \mathrm{min}$.)

The ketoacetate 9a becomes the major product, if a large excess of iodobenzene diacetate is used. The addition of 2 equiv. of sodium acetate favors the oxidative cleavage to give benzaldehyde rather than the epoxidation or the formation of the ketoacetate. The use of a more polar solvent retards the reaction and largely favors the formation of the epoxide.

In order to confirm that the ketoacetate did not arise from a ring opening reaction of the firstformed epoxide, an authentic sample of trans-stilbene oxide 8a was allowed to react under the same conditions. No reaction occurred, and the epoxide could be entirely recovered. 
Furthermore, the reaction of cis-stilbene $\mathbf{7 b}$ afforded a 59/41 mixture of cis-stilbene oxide $\mathbf{8 b}$ (d.e. $=94 \%$ ) and the ketoacetate 9a, the epoxidation reaction being nearly completely stereospecific.

In order to generalize the reactions and therefore to propose a mechanistic pathway for the formation of the ketoacetate, we have studied the reactivity of several differently substituted olefins. The results are presented in Table 4.

In the case of olefins bearing aromatic groups (entries 1-6), the reaction always gave rise to a mixture of the corresponding epoxide and regioisomeric ketoacetate (or hydroxyacetate in a particular case). However, the oxidation of alkyl-substituted olefins (entries 7-8) gave the epoxide exclusively without any trace of ketoacetate.

Table 4. Oxidation of various olefins

Entry Substrate

All the reactions were performed using the conditions listed in Scheme 4 (entry 1). 
We have then compared the catalytic activity of several ruthenium complexes for the oxidation of trans-stilbene. The results are presented in Table 5.

Our binaphthyl-substituted $\mathrm{Ru}(\mathrm{III})$ catalyst $6 \mathbf{c}$ and $\mathrm{RuCl}_{2}\left(\mathrm{PPh}_{3}\right)_{3}$ seem to have nearly the same catalytic activity with similar epoxide/ketoacetate ratio's. In contrast, Beller ${ }^{23}$ has shown that, under the same experimental conditions, the ruthenium(pybox) catalyst (A) gave rise to the exclusive formation of the epoxide in $80 \%$ yield. Interestingly, ruthenium trichloride exclusively afforded the ketoacetate without any trace of the epoxide.

Table 5. Oxidation of trans-stilbene using various catalysts

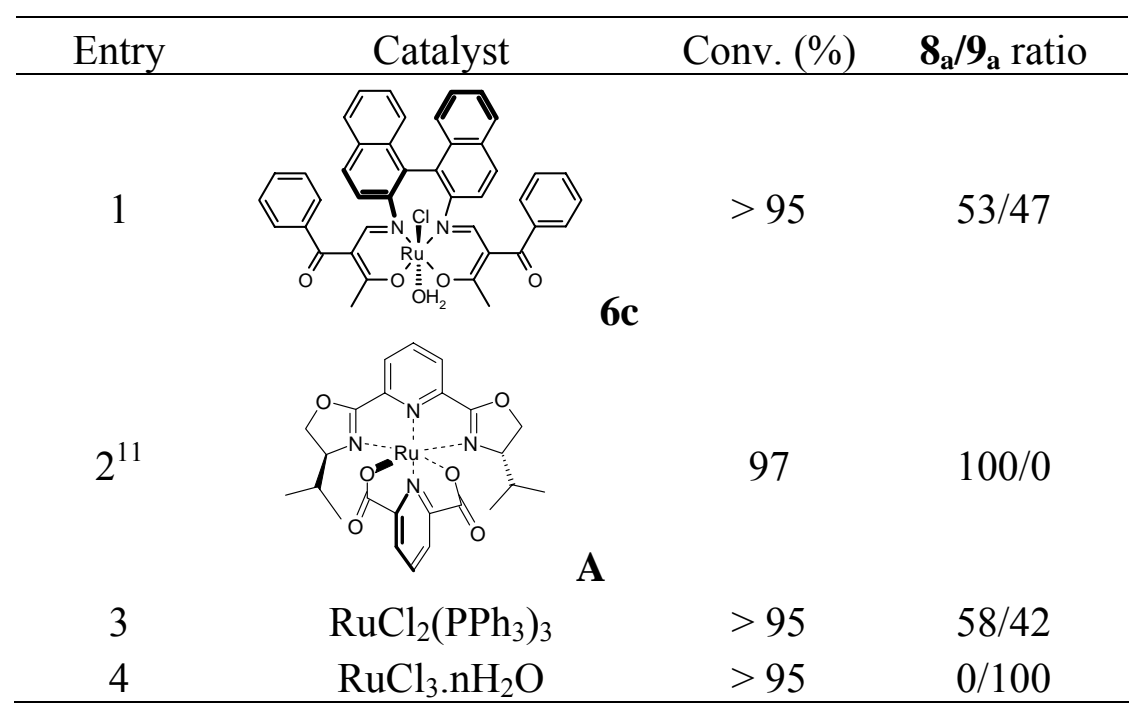

The enantiomeric excess obtained with the catalyst $6 \mathbf{c}$ is low (4\% e.e.). The reason of this behavior remains unclear. It may be possible that one particular mode of ligation by the tetradentate ligand around ruthenium atom in the octahedral complex would be responsible to the absence of selectivity. In the case of classical Mn-salen complexes, it has been proven that the geometry around the metal center was square planar in the case of cationic complexes with two residual ligands in apical positions, trans to each other or slightly square pyramidal in the case of neutral complexes with the residual ligand perpendicular to the plane. ${ }^{24}$ Che has shown ${ }^{15 \mathrm{~d}}$ that, in the case of binaphthyl-salen manganese complexes, the geometry, established by X-ray crystallography around the manganese atom, was octahedral with the Schiff base ligand bound to the metal center in a cis- $\beta$ configuration, as shown on Scheme 5. The binaphthyl moiety enforces the complexes to adopt a non-square-planar geometry. In our case, it is highly probable, but we were unable to obtain satisfactory monocrystals for X-ray analysis, that the binaphthylsubstituted ruthenium(III) complexes adopt such a mode of ligation. In that case, a much more open space, with various available pathways for the incoming substrate is present around the metal and would be therefore responsible of the absence of enantioselectivity. 


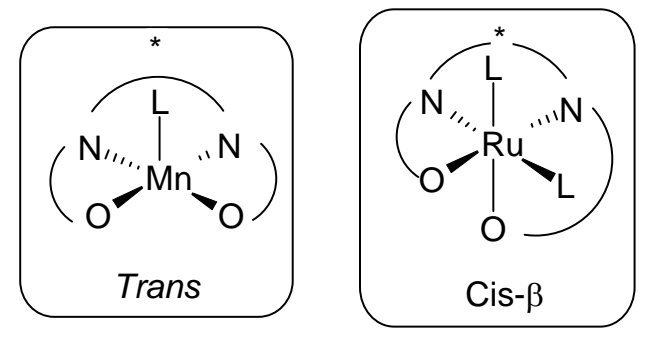

\section{Scheme 5}

With those results in hand, we propose mechanistic pathways for both the epoxidation and the unexpected ketoacetate formation. To the best of our knowledge, the direct formation of $\alpha$ ketoacetates by oxidation of an olefin has not been reported. We discovered, some years ago, the catalytic oxidative transformation of olefins to $\alpha$-ketols, ${ }^{6}$ and an extensive study was performed. ${ }^{6,25-27}$ Thus, the reactions of various alkenes with peracetic acid in the presence of a catalytic amount of ruthenium trichloride in a three component solvent system $\left(\mathrm{CH}_{3} \mathrm{CN} / \mathrm{CH}_{2} \mathrm{Cl}_{2} / \mathrm{H}_{2} \mathrm{O}\right.$ : 1/1/1) gave the corresponding $\alpha$-ketols regio- and stereoselectively in good yields. The mechanism was rationalized as follows: the reaction of the $\mathrm{Ru}(\mathrm{III})$ complex with peracetic acid affords a $\mathrm{Ru}(\mathrm{V})=\mathrm{O}$ species which undergoes reaction with olefins to give a cationic species. Nucleophilic attack of water before ring closure would give the epoxide or a subsequent $\beta$-elimination of ruthenium hydride would give the $\alpha$-ketol. ${ }^{6}$ In our case, such a mechanistic pathway has to be ruled out for two reasons. Firstly, the reaction is inhibited by polar solvents such as acetonitrile that would stabilize cationic species. Secondly, in most cases, the regioselectivity observed in the formation of ketoacetates is very low.

Three different pathways are usually proposed to explain the mechanism of the oxygen transfer in Mn-salen catalyzed asymmetric epoxidations: a concerted path (A), a path proceeding via radical intermediates $(\mathrm{B})$ and a metallaoxetane path $(\mathrm{C}){ }^{28}$

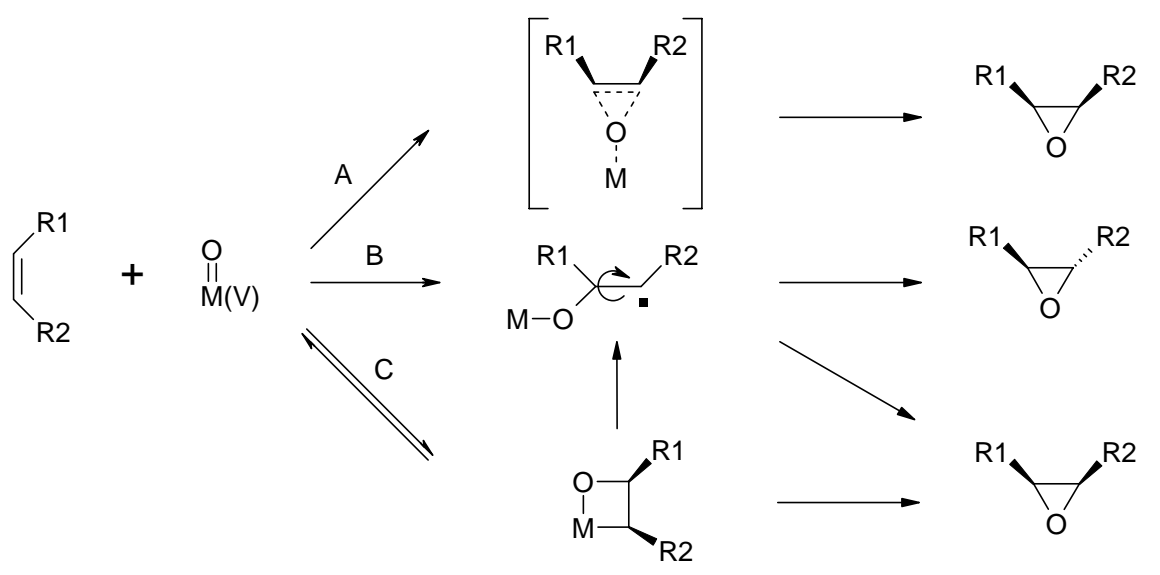

\section{Scheme 6}


Type-A mechanism can be excluded. Indeed, when the epoxide (trans-stilbene oxide) is allowed to react with either the binaphthyl-substituted ruthenium complex or ruthenium trichloride in the presence of iodobenzene diacetate, it remains unchanged. Type-B mechanism should also be ruled out, because the reaction of cis-stilbene is completely stereospecific under the standard reaction conditions. Another proposal has been reported to explain the mechanism of oxygen transfer from the oxo-manganese complex to the olefin, namely the formation of an oxometallacycle (type-C). ${ }^{29-30}$

The formation of mixtures of regioisomeric ketoacetates together with the stereospecific formation of epoxides can only be explained by assuming the intermediate formation of a ruthenaoxetane.

In the case of manganese-salen complexes, the commonly postulated intermediate, a manganese-oxo species, should keep the slightly pyramidal conformation of the complex. The formation of a manganaoxetane should result in the obtention of diastereoisomeric octahedral or pseudo-octahedral structures with a phenolic oxygen in an axial position. However, binaphthylsubstituted ruthenium complexes should be characterized, as previously proposed, by a cis mode of ligation (see Scheme 5). The formation of ruthenacycles, occurring without any change of geometry around the metal center, would therefore be highly favored, as in the case of $\mathrm{RuCl}_{2}\left(\mathrm{PPh}_{3}\right)_{3}$.

The formation of ketoacetates can easily be explained by nucleophilic attack of acetate that would result in the ring-opening of the cycle and the subsequent elimination of a rutheniumhydride species. The obtention of regioisomeric ketoacetates reflects the diastereoisomeric ratio of the two ruthenaoxetanes, the latter being probably dependent mostly upon the steric environment around the metal-oxo species. The epoxide/ketoacetates ratio is dependent either upon the stability, or the steric crowding of the oxetane and the nature of the ligands bound to ruthenium. We have shown that the reaction of non-aromatic olefins only gave rise to the formation of epoxides. In that case, the assumed instability and the short life-time of the ruthenacycles would preclude the nucleophilic attack in favor of the intramolecular cyclization, contrary to the case of olefins bearing aromatic substituents which can give rise to more stable intermediates.

The postulated mechanism of the ruthenium catalyzed oxidation of olefins using iodobenzene diacetate as terminal oxidant is shown in Scheme 7. The ruthenium(III) complex is first oxidized into a ruthenium(V)-oxo species which reacts with the olefin to give diastereoisomeric ruthenaoxetanes. Depending upon the electronic and steric properties of the ligands, the ruthenaoxetane intermediate could either directly give the epoxide (cycle A) or be attacked by acetate to afford regioisomeric ketoacetates together with the ruthenium(III)-hydride species which is further oxidized into the ruthenium(V)-oxo (cycle B). 


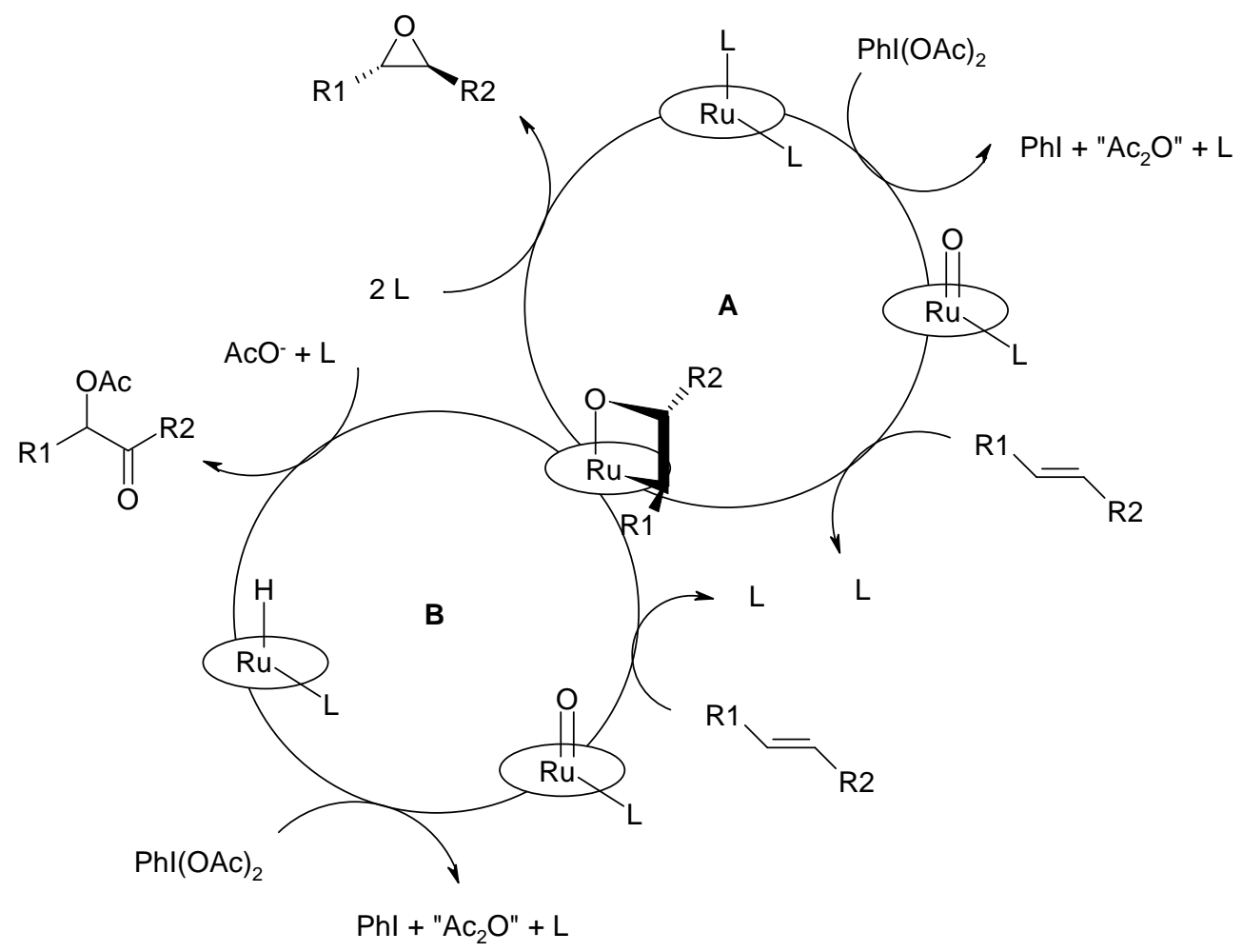

Scheme 7

In conclusion, we synthesized a new type of ruthenium(III) complexes characterized by a binaphthyl moiety as chiral backbone and two 1,3-dicarbonyl units, and showed their reactivity as catalysts for the epoxidation of olefins. The enantiomeric excesses obtained were very low, but this study led us to the discovery of a new type of aromatic olefin oxidation leading directly to ketoacetates.

\section{Experimental Section}

General Procedures. Infrared (IR) spectra were recorded on a Shimadzu FT-IR-4100 spectrometer. ${ }^{1} \mathrm{H}$ and ${ }^{13} \mathrm{C}$ NMR spectra were measured on a JEOL JNM GSX-270 using $\mathrm{CDCl}_{3}$ as a solvent and with tetramethylsilane as internal standard. Coupling constants $(\mathrm{J})$ are expressed in $\operatorname{Hertz}(\mathrm{Hz})$.

Analytical GC measurements were carried out on a Shimadzu GC-12A gas chromatograph (inj.: $250^{\circ} \mathrm{C}$, det.: $250^{\circ} \mathrm{C}$, column: $100^{\circ} \mathrm{C}$, then $10^{\circ} \mathrm{C} / \mathrm{min}$. and finally $250^{\circ} \mathrm{C}$ ). Chiral HPLC analyses were performed on JASCO TRI-ROTAR-VI system with a JASCO MULTI 340 UV detector by using $250 \mathrm{~mm}$ x $4.6 \mathrm{~mm}$ analytical columns (DAICEL chiralpak AS, chiralcel OD-H and $\mathrm{OB}-\mathrm{H})$. 
Solvents: THF and chlorobenzene were distilled on sodium benzophenone ketyl prior to use. Toluene was distilled on sodium. Dichloromethane and dimethylformamide were distilled on calcium hydride. Methanol was distilled on magnesium. Ethanol was distilled on sodium.

2-Benzoyl-3-oxo-butyraldehyde (1c). A mixture of benzoylacetone (15 mmol, $2.43 \mathrm{~g}$ ) and trimethylorthoformate $(26 \mathrm{mmol}, 2.76 \mathrm{~g})$ in acetic anhydride $(45 \mathrm{mmol}, 4.59 \mathrm{~g})$ is heated at $120^{\circ} \mathrm{C}$ for $7 \mathrm{~h}$. After cooling, acetic anhydride is evaporated in vacuo to give a black solid. Recrystallization from ethyl acetate/hexane affords pure enol ether 5c $(2.14 \mathrm{~g}, 70 \%)$ as brown needles. $\mathrm{mp}=43^{\circ} \mathrm{C}$. IR (KBr): 1676, 1645, 1628, 1622, 1618, 1612, 1489, 1447, 1413, 1359, 1304, 1271, 1229, 1201, 1170, 1144, 1082, 1026, 964, 912, 768, 696. ${ }^{1} \mathrm{H}$ NMR: 2.22 (s, 3H, $\left.\mathrm{CH}_{3}\right), 3.81\left(\mathrm{~s}, 3 \mathrm{H}, \mathrm{OCH}_{3}\right), 7.42-7.89(\mathrm{~m}, 6 \mathrm{H}, \mathrm{Ph}$ and $\mathrm{C} \underline{\mathrm{H}}=\mathrm{C}-\mathrm{OMe}) .{ }^{13} \mathrm{C}$ NMR: 27.5, 62.6, 121.4, 128.5, 129.1, 133.4, 137.1, 162.6, 194.0, 194.6. MS (FAB): $205\left(\mathrm{M}^{+}\right)$. Elemental analysis for $\mathrm{C}_{12} \mathrm{H}_{12} \mathrm{O}_{3}(\%)$ : Calculated (C: $\left.70.58 \mathrm{H}: 5.92\right)$ Found (C: $\left.70.23 \mathrm{H}: 5.78\right)$.

A $5 \% \mathrm{HCl}$ solution is added to a solution of the enol ether $\mathbf{5 c}(8.82 \mathrm{mmol}, 1.8 \mathrm{~g})$ in $20 \mathrm{ml}$ of THF. The orange solution is stirred at room temperature for $2 \mathrm{~h}$. Water $(10 \mathrm{ml})$ is added and the mixture is extracted with diethyl ether. The combined organic phases are dried over sodium sulfate and concentrated in vacuo. 2-Benzoyl-3-oxo-butyraldehyde $(1.65 \mathrm{~g})$ is obtained $(80 \%$ pure, contaminated by $16 \%$ of benzoylacetone) as an orange oil and used without further purification.

2-Hydroxy-4,4-dimethyl-6-oxo-cyclohex-1-enecarbaldehyde (1d). Dimethylformamide dimethylacetal (20 mmol, 2.38g) is added dropwise to solid dimedone (20 mmol, $2.80 \mathrm{~g})$, under inert atmosphere, without solvent. The bright yellow solution is stirred for 20 minutes at room temperature then for 10 minutes at $60^{\circ} \mathrm{C}$. The mixture is diluted with ethyl acetate $(100 \mathrm{ml})$ and concentrated in vacuo. Pure enamine 5d (3.87 g, 99\%) is obtained as a bright yellow solid and used without further purification. $\mathrm{mp}=91-93^{\circ} \mathrm{C}$. IR $(\mathrm{KBr}): 1662,1590,1584,1427,1373,1311$, 1261, 1136, 1105, 1043, 978. ${ }^{1} \mathrm{H}$ NMR: 1.06 (s, 6H, $2 \mathrm{CH}_{3}$ ), 2.34 (s, 4H, $2 \mathrm{CH}_{2}$ ), 3.20 and 3.41 $\left(2 \mathrm{~s}, 6 \mathrm{H},-\mathrm{N}\left(\mathrm{CH}_{3}\right)_{2}\right), 8.00$ (s, $\left.1 \mathrm{H}, \mathrm{C}=\mathrm{C} \underline{\mathrm{H}}-\mathrm{NMe}_{2}\right) .{ }^{13} \mathrm{C} \mathrm{NMR}: 27.8,30.1,44.0,47.8,51.5,107.5$, 160.9, 194.6. MS (FAB): $196\left(\mathrm{M}^{+}\right)$. Elemental analysis for $\mathrm{C}_{11} \mathrm{H}_{17} \mathrm{NO}_{2}(\%)$ : Calculated (C: 67.66 H: 8.78 N: 7.17) Found (C: 67.69 H: 8.86 N: 6.96).

A $1 \% \mathrm{HCl}$ solution is added to a solution of the enamine $5 \mathbf{d}(15 \mathrm{mmol}, 2.93 \mathrm{~g})$ in $20 \mathrm{ml}$ of THF. Decoloration occurs and the slightly yellow solution is stirred at room temperature for $2.5 \mathrm{~h}$. Water $(30 \mathrm{ml})$ is added and the mixture is extracted with ethyl acetate. The combined organic phases are dried over sodium sulfate and concentrated in vacuo. Pure 2-Hydroxy-4,4-dimethyl-6oxo-cyclohex-1-enecarbaldehyde $(2.38 \mathrm{~g}, 94 \%, 93 \%$ from dimedone $)$ is obtained as an orange powder and used without further purification. $\mathrm{mp}=73-75^{\circ} \mathrm{C}$. IR (KBr): $1670,1415,1385,1325$, 1175, 1142, 1040, 978, 781, 646. ${ }^{1} \mathrm{H}$ NMR: 1.11 (s, 6H, $\left.2 \mathrm{CH}_{3}\right), 2.34$ (s, 4H, $\left.2 \mathrm{CH}_{2}\right), 2.54(\mathrm{~s}, 2 \mathrm{H}$, $\mathrm{CH}_{2}$ ), 9.55 (s, 1H, CHO). ${ }^{13} \mathrm{C}$ NMR: 28.1, 31.5, 45.1, 50.5, 112.8, 190.2, 194.7, 194.8. MS (FAB): $169\left(\mathrm{M}^{+}\right)$. Elemental analysis for $\mathrm{C}_{9} \mathrm{H}_{12} \mathrm{O}_{3}(\%)$ : Calculated (C: $64.27 \mathrm{H}:$ 7.19) Found (C: $64.59 \mathrm{H}: 7.51)$. 


\section{Synthesis of ligands}

A mixture of (2R)-binaphthyldiamine and aldehyde (2 eq.) in ethanol and 1,2-dichloroethane $(1: 2)$ is heated at $70^{\circ} \mathrm{C}$ for $3-26 \mathrm{~h}$. The solvents are evaporated under reduced pressure and the crude mixture is purified as mentioned to afford pure ligands.

2-[1-\{2'-[(E)-2-(Adamantan-2-yloxycarbonyl)-3-oxo-but-1-enylamino]-[1,1']binaphthalenyl2-ylamino\}-meth-(E)-ylidene]-3-oxo-butyric acid adamantan-2-yl ester (3a). Column chromatography, EtOAc/hexane: 1:4, 29\%, yellow powder, $\mathrm{mp}=118-121^{\circ} \mathrm{C}$. IR $(\mathrm{KBr}): 2909$, 2853, 1697, 1691, 1631, 1618, 1595, 1562, 1512, 1470, 1410, 1383, 1340, 1296, 1244, 1211, 1157, 980, 810, 746. ${ }^{1} \mathrm{H}$ NMR: 0.8-2.1 (m, 28H, adamantyl), 2.30 (s, 6H, $2 \mathrm{CH}_{3}$ ), 5.05 (m, 2H, 2 -CH-O), 6.75-8.25 (m, 12H, Ph), 8.67 (d, 2H, =CH-N-). MS (FAB): $777\left(\mathrm{M}^{+}\right)$. Elemental analysis for $\mathrm{C}_{50} \mathrm{H}_{52} \mathrm{~N}_{2} \mathrm{O}_{6}(\%)$ : Calculated (C: $\left.77.29 \mathrm{H}: 6.75\right)$ Found (C: $\left.76.92 \mathrm{H}: 6.77\right)$.

2-[1-[2'-((E)-2-Methoxycarbonyl-3-oxo-but-1-enylamino)-[1,1']binaphthalenyl-2-ylamino]meth-(E)-ylidene]-3-oxo-butyric acid methyl ester (3b). Recrystallization from EtOAc/hexane, $69 \%$, tan powder, $\mathrm{mp}=135-138^{\circ} \mathrm{C}$. IR $(\mathrm{KBr}): 1711,1636,1595,1564,1514$, 1437, 1412, 1300, 1248, 1217, 1076, 812. ${ }^{1} \mathrm{H}$ NMR: 2.42 (s, 6H, $\left.2 \mathrm{CH}_{3}\right), 3.87$ (s, 6H, $2 \mathrm{OCH}_{3}$ ), $7.22(\mathrm{~d}, 2 \mathrm{H}, \operatorname{Ar}, \mathrm{J}=8.4), 7.45(\mathrm{dd}, 2 \mathrm{H}, \operatorname{Ar}, \mathrm{J}=8.4), 7.62(\mathrm{dd}, 2 \mathrm{H}, \operatorname{Ar}, \mathrm{J}=7.9), 7.91(\mathrm{~d}, 2 \mathrm{H}, \operatorname{Ar}, \mathrm{J}$ = 7.9), 8.13 (d, 2H, Ar, J = 8.4), 8.35 (d, 2H, Ar, J = 9.4), 8.70 (d, 2H, =C $\underline{H}(\mathrm{NHAr}), \mathrm{J}=12.9)$, 12.48 (d, 2H, 2 NHAr, J = 12.9). ${ }^{13} \mathrm{C}$ NMR: 30.7, 51.1, 103.0, 115.2, 120.2, 125.3, 125.9, 127.9, 128.7, 131.6, 133.0, 135.9, 151.3, 167.1, 199.4. MS (FAB): $537\left(\mathrm{M}^{+}\right)$. Elemental analysis for $\mathrm{C}_{32} \mathrm{H}_{28} \mathrm{~N}_{2} \mathrm{O}_{6}(\%)$ : Calculated (C: $\left.71.63 \mathrm{H}: 5.26 \mathrm{~N}: 5.22\right)$ Found (C: $\left.71.72 \mathrm{H}: 5.22 \mathrm{~N}: 5.17\right)$.

(E)-3-Benzoyl-4-[2'-((E)-2-benzoyl-3-oxo-but-1-enylamino)-[1,1']binaphthalenyl-2-ylamino] -but-3-en-2-one (3c). Recrystallization from EtOAc/hexane, 59\%, bright yellow powder, mp = 115-118 ${ }^{\circ}$. IR (KBr): 1630, 1595, 1560, 1510, 1388, 1367, 1292, 1265, 1234, 1131, 1022, 895.

${ }^{1} \mathrm{H}$ NMR: 2.19 (s, 6H, $2 \mathrm{CH}_{3}$ ), 7.00-8.16 (m, 24H, binaphthyl, $\mathrm{Ph}$ and $\left.=\mathrm{C} \underline{\mathrm{H}}(\mathrm{NHAr})\right), 12.25$ (d, 2H, 2 NHAr, J = 12.4). ${ }^{13} \mathrm{C}$ NMR: 30.3 , 51.1, 113.0, 114.7, 120.1, 125.2, 125.9, 128.0, 128.5, $128.7,129.1,129.2$, 131.6, 131.7, 133.0, 135.7, 140.0, 151.8, 167.1, 194.9, 200.1 . MS (FAB): $629\left(\mathrm{M}^{+}\right)$. Elemental analysis for $\mathrm{C}_{42} \mathrm{H}_{32} \mathrm{~N}_{2} \mathrm{O}_{4}(\%)$ : Calculated (C: $\left.80.24 \mathrm{H}: 5.13 \mathrm{~N}: 4.46\right)$ Found (C: $79.32 \mathrm{H}: 5.26 \mathrm{~N}: 4.37)$.

$\boldsymbol{N}, \boldsymbol{N}$ '-Bis-(5,5-dimethyl-1,3-cyclohexanedione)-binaphthyldiamine (3d). Column chromatography, EtOAc, $88 \%$, pale yellow powder, $\mathrm{mp}=160-163^{\circ} \mathrm{C}$. IR $(\mathrm{KBr}): 1670,1601,1585,1562,1512$, 1473, 1429, 1305, 1290, 1248, 1217, 1134, 1016, 978, 814, 748. ${ }^{1} \mathrm{H}$ NMR: 0.90 and 0.93 (2s, $\left.12 \mathrm{H}, 4 \mathrm{CH}_{3}\right), 2.14,2.18$ and $2.26\left(3 \mathrm{~s}, 8 \mathrm{H}, 4 \mathrm{CH}_{2}\right), 7.06(\mathrm{~d}, 2 \mathrm{H}, \mathrm{Ar}, \mathrm{J}=8.4), 7.30(\mathrm{~d}, 2 \mathrm{H}, \mathrm{Ar}, \mathrm{J}=$ 8.4), 7.47 (d, 2H, Ar, J = 7.9), 7.86 (d, 2H, Ar, J = 8.9), 7.99 (d, 2H, Ar, J = 8.4), 8.22 (d, 2H, Ar, $\mathrm{J}=8.9), 8.65(\mathrm{~d}, 2 \mathrm{H},-\mathrm{C}=\mathrm{C} \underline{\mathrm{HN}}, \mathrm{J}=13.4), 12.44(\mathrm{~d}, 2 \mathrm{H}, 2 \mathrm{~N} \underline{\mathrm{HAr}}, \mathrm{J}=13.4) .{ }^{13} \mathrm{C}$ NMR: 28.3, 28.4, 30.7, 51.2, 109.4, 114.9, 120.4, 125.4, 126.2, 128.0, 128.7, 131.9, 132.8, 135.4, 149.6, 196.1, 199.2 . MS (FAB): $585\left(\mathrm{M}^{+}\right)$. Elemental analysis for $\mathrm{C}_{38} \mathrm{H}_{36} \mathrm{~N}_{2} \mathrm{O}_{4}(\%)$ : Calculated (C: $78.06 \mathrm{H}$ : $6.21 \mathrm{~N}: 4.79)$ Found (C: $77.03 \mathrm{H}: 6.25 \mathrm{~N}: 4.53)$. 


\section{Syntheses of ruthenium (III) complexes}

A mixture of ligand and DBU (5 eq.) in anhydrous DMF ( $3 \mathrm{ml} / 0.1 \mathrm{mmol}$ of ligand) is stirred at room temperature for 5 minutes. $\mathrm{K}_{2}\left[\mathrm{RuCl}_{5}\left(\mathrm{H}_{2} \mathrm{O}\right)\right]$ (2 eq.) is added at once and the mixture is heated and stirred at $120^{\circ} \mathrm{C}$ for $24 \mathrm{~h}$. After cooling to room temperature, water is added to precipitate the complex which is filtrated and washed several times with water. Purification of the crude solid by silica gel preparative plates (acetone- $\mathrm{CH}_{2} \mathrm{Cl}_{2}: 2 / 3$ ) followed by drying under vacuum affords pure complex.

$\boldsymbol{N}, \boldsymbol{N}$ '-Bis-(2-methoxycarbonyl-3-oxobutylidene)-binaphthyldiamine ruthenium (III) (6b). Yield, 30\%, dark red solid, IR (KBr): 3411, 1701, 1697, 1692, 1686, 1676, 1664, 1655, 1560, $1433,1422,1395,1383,1375,1365,1359,1273,1255,1207,1084$. MS (FAB): $671\left(\mathrm{M}^{+}-\mathrm{H}_{2} \mathrm{O}\right)$, $636\left(\mathrm{M}^{+}-\mathrm{H}_{2} \mathrm{O}-\mathrm{Cl}\right)$.

$\boldsymbol{N}, \boldsymbol{N}$ '-Bis-(2-benzoyl-3-oxobutylidene)-binaphthyldiamine ruthenium (III) (6c). Yield, 33\%, dark green solid, IR (KBr): 1911, 1701, 1635, 1626, 1593, 1554, 1549, 1448, 1420, 1414, 1395 , 1389, 1377, 1277, 885. MS (FAB): $823\left(\mathrm{M}^{+}-\mathrm{H}_{2} \mathrm{O}+\mathrm{C}_{3} \mathrm{H}_{6} \mathrm{O}\right), 786\left(\mathrm{M}^{+}-\mathrm{H}_{2} \mathrm{O}+\mathrm{Na}\right), 763\left(\mathrm{M}^{+}-\right.$ $\left.\mathrm{H}_{2} \mathrm{O}\right), 728\left(\mathrm{M}^{+}-\mathrm{H}_{2} \mathrm{O}-\mathrm{Cl}\right)$.

$\boldsymbol{N}, \boldsymbol{N}$ '-Bis-(5,5-dimethyl-1,3-cyclohexanedione)-binaphthyldiamine ruthenium (III) (6d): (15\%, dark red solid) IR (KBr): 1701, 1551, 1437, 1302. MS (FAB): $779\left(\mathrm{M}^{+}-\mathrm{H}_{2} \mathrm{O}+\mathrm{C}_{3} \mathrm{H}_{6} \mathrm{O}\right)$, $744\left(\mathrm{M}^{+}-\mathrm{H}_{2} \mathrm{O}+\mathrm{Na}\right), 720\left(\mathrm{M}^{+}-\mathrm{H}_{2} \mathrm{O}\right), 684\left(\mathrm{M}^{+}-\mathrm{H}_{2} \mathrm{O}-\mathrm{Cl}\right)$.

\section{General procedure for the oxidation of olefins with ruthenium (III) catalysts}

A $25 \mathrm{ml}$ Schlenk-tube is charged with the olefin, ruthenium catalyst (5\% mol.) and toluene (15 $\mathrm{ml} / \mathrm{mmol}$ of olefin). Iodobenzene diacetate (3 eq.) is then added at once at room temperature and the mixture is stirred for $90 \mathrm{~h}$. A 5\% sodium sulfite solution is added and the mixture is extracted with ethyl acetate. The combined organic phases are washed with water, dried over magnesium sulfate and concentrated in vacuo. Purification on silica gel preparative plates (hexane/ethyl acetate) affords pure epoxide and/or ketoacetate.

\section{Oxidation of trans-stilbene 7a}

A $25 \mathrm{ml}$ Schlenk-tube is charged with trans-stilbene $(0.21 \mathrm{mmol}, 38 \mathrm{mg})$, N,N'-Bis-(2-benzoyl3-oxobutylidene)-binaphthyldiamine ruthenium(III) 6c $(0.01 \mathrm{mmol}, 7 \mathrm{mg})$ and toluene $(5 \mathrm{ml})$. Iodobenzene diacetate $(0.63 \mathrm{mmol}, 204 \mathrm{mg})$ is then added at once at room temperature and the mixture is stirred for $90 \mathrm{~h}$. A 5\% sodium sulfite solution is added and the mixture is extracted with ethyl acetate. The combined organic phases are washed with water, dried over magnesium sulfate and concentrated in vacuo. Purification on silica gel preparative plates (hexane/ethyl acetate 75/25) affords pure trans-stilbene oxide (16 mg, 39\%, compared with an authentic sample) and pure acetic acid 2-oxo-1,2-diphenyl-ethyl ester (17 mg, 32\%, colorless oil). Global yield: $71 \%$.

Acetic acid 2-oxo-1,2-diphenyl-ethyl ester (9a). IR (neat): 3090, 2937, 1740, 1697, 1597, 1581, 1495, 1449, 1373, 1234, 1228, 1180, 1161, 1080, 1057, 1030, 1005, 972, 934, 758, 696. ${ }^{1} \mathrm{H}$ 
NMR: $2.20\left(\mathrm{~s}, 3 \mathrm{H}, \mathrm{CH}_{3}\right), 6.86(\mathrm{~s}, 1 \mathrm{H},-\mathrm{CH}-\mathrm{OAc}), 7.33-7.50(\mathrm{~m}, 8 \mathrm{H}, \mathrm{Ph}), 7.92(\mathrm{~m}, 2 \mathrm{H}, \mathrm{Ph}) .{ }^{13} \mathrm{C}$ NMR: 20.7, 77.7, 128.6, 128.7, 128.8, 129.1, 129.3, 133.4, 133.7, 134.7, 170.5, 193.7. MS (EI): $254\left(\mathrm{M}^{+}\right)$.

\section{Acknowledgements}

This work was supported by the Research for the Future Program, Japan Society for the Promotion of Science (Fellowship to L.P.).

\section{References}

1. Murahashi, S.-I. Angew. Chem., Int. Ed. 1995, 34, 2443.

2. (a) Murahashi, S.-I.; Komiya, N. Oxidation reaction, In Ruthenium in Organic Synthesis, S.I. Murahashi, Ed., Wiley-VCH: Weinheim, 2004; pp 53-93. (b) Murahashi, S.-I. Komiya, N., Ruthenium catalyzed oxidations, In Modern Organic Methods, J.-E. Backvall, Ed., Wiley-VCH: Weinheim, 2004; pp 165-191.

3. Murahashi, S.-I.; Naota, T.; Yonemura, K. J. Am. Chem. Soc. 1988, 110, 8256.

4. a) Murahashi, S.-I.; Komiya, N.; Terai, H.; Nakae, T. J. Am. Chem. Soc. 2003, 125, 15312 b) Murahashi, S.-I.; Komiya, N.; Terai, H. Angew. Chem. Int. Ed. 2005, 44, 6931.

5. Murahashi, S.-I.; Naota, T.; Kuwabara, T.; Saito, T.; Kumobayashi, H.; Akutagawa, S. J. Am. Chem. Soc. 1990, 112, 7820.

6. Murahashi, S.-I.; Saito, T.; Hanaoka, H.; Murakami, Y.; Naota, T.; Kumobayashi, H.; Akutagawa, S. J. Org. Chem. 1993, 58, 2929.

7. Murahashi, S.-I.; Oda, Y.; Naota, T. J. Am. Chem. Soc. 1992, 114, 7913.

8. (a) Beller, M.; Bolm, C., Eds. Transition Metals for Organic Synthesis, $2^{\text {nd }}$ Edn.; WileyVCH: Weinheim, 2004. (b) Jacobsen, E.N.; Pfaltz, A.; Yamamoto, H., Eds. Comprehensive Asymmetric Catalysis, Springer: Berlin, 1999.

9. (a) Jacobsen, E.; Zhang, W.; Gulter, M. L. J. Am. Chem. Soc. 1990, 112, 2801. (b) For review, see: Jacobsen, N. E., In Catalytic Asymmetric Synthesis, Ojima, I. Ed., VCH: Weinheim, 1993; pp 159-202.

10. (a) Irie, R.; Ito, Y.; Katsuki, T. Synlett 1991, 267. (b) For review, see: Katsuki, T. Synlett 2003, 281.

11. Nagata, T.; Imagawa, K.; Yamada, T.; Mukaiyama, T. Bull. Chem. Soc. Jpn. 1995, 68, 1455.

12. Murahashi, S.-I.; Noji, S.; Hirabayashi, T.; Komiya, N. Synlett 2004, 1739.

13. Murahashi, S.-I.; Noji, S.; Komiya, N. Adv. Synth. Catal. 2004, 346, 195.

14. Murahashi, S.-I.; Noji, S.; Komiya, N. Tetrahedron: Asymmetry 2006, 16, 3527.

15. (a) Bernardo, K.; Robert, A.; Dahan, F.; Meunier, B. New J. Chem. 1995, 19, 129. (b) Bernardo, K.; Leppard, S.; Robert, A.; Commenges, G.; Dahan, F.; Meunier, B. Inorg. 
Chem. 1996, 35, 387. (c) Nishinaga, A.; Yamato, H.; Abe, T.; Maruyama, K.; Matsuura, T. Tetrahedron Lett. 1988, 29, 6309. (d) Cheng, M. C.; Chan, M. C. W.; Peng, S. M.; Cheung, K. K.; Che, C. M. J. Chem. Soc. Dalton Trans. 1997, 3479. (e) Ho, C. W.; Cheng, W. C.; Cheng, M. C.; Peng, S. M.; Cheng, K. F.; Che, C. M. J. Chem. Soc. Dalton Trans. 1996, 405

16. Nudelman, A.; Kelner, R.; Broida, N.; Gottlieb, H. E. Synthesis 1989, 387

17. Meerwein, H.; Florian, W.; Schön, N.; Stopp, G. Liebigs Ann. Chem. 1961, 641, 1.

18. Kocevar, M.. Polanc, S.; Vercek, B.; Tisler, M. Liebigs Ann. Chem. 1990, 501.

19. (a) Kureshy, R. I.; Khan, N. H.; Abdi, S. H. R.; Iyer, P. J. Mol. Catal. A: Chem. 1997, 124, 91. (b) Kureshy, R. I.; Khan, N. H.; Abdi, S. H. R.; Bath, A. K. J. Mol. Catal. A: Chem. 1996, 110, 33.

20. (a) Barf, G. A.; Sheldon, R. A. J. Mol. Catal. A: Chem. 1995, 102, 23. (b) Barf, G. A.; van den Hoek, D.; Sheldon, R. A. Tetrahedron 1996, 52, 12971.

21. Nishiyama, H.; Shimada, T.; Itoh, H.; Sugiyama, H.; Motoyama, Y. Chem. Commun. 1997, 1863.

22. (a) Bhor, S.; Anilkumar, G.; Tse, M. K.; Klawonn, M.; Döbler, C.; Bitterlich, B.; Grotevendt, A.; Beller, M. Org. Lett. 2005, 7, 3393 and references cited therein b) see also: Arends, I. W. C. E. Angew. Chem. Int. Ed. 2006, 45, 6250.

23. Tse, M. K.; Bhor, S.; Klawonn, M.; Döbler, C.; Beller, M. Tetrahedron Lett. 2003, 44, 7479.

24. Pospisil, P. J.; Carsten, D. H.; Jacobsen, E. N. Chem. Eur. J. 1996, 2, 974.

25. Plietker, B. J. Org. Chem. 2003, 68, 7123.

26. Plietker, B. J. Org. Chem. 2004, 69, 8287 and references cited therein.

27. Shing, T. K. M.; Tam, E. K. W.; Tai, V. W.-F.; Chung, I. H. F.; Jiang, Q. Chem. Eur. J. 1996, 2, 50 .

28. Linker, T. Angew. Chem., Int. Ed. 1997, 36, 2060.

29. Norrby, P.-O.; Linde, C.; Akermark, B. J. Am. Chem. Soc. 1995, 117, 11035.

30. Méou, A.; Garcia, M.-A.; Brun, P. J. Mol. Catal. A: Chem. 1999, 138, 221. 